\title{
LA RELACIÓN ENTRE LA UNIÓN EUROPEA Y EL CONVENIO EUROPEO DE DERECHOS HUMANOS
}

\author{
LUIS MARÍA DÍEZ-PICAZO \\ Catedrático de Derecho Constitucional
}

La relación entre la Unión Europea y el Convenio Europeo de Derechos Humanos presenta varias facetas. La primera en el tiempo es la utilización del Convenio Europeo de Derechos Humanos por el Tribunal de Justicia de las Comunidades Europeas, a fin de dotar de protección a los derechos fundamentales en el derecho comunitario. Presionado por los Tribunales Constitucionales italiano y alemán desde finales de los años sesenta, el Tribunal de Justicia de las Comunidades Europeas se vio forzado a establecer que los derechos fundamentales vinculan a las instituciones comunitarias. En efecto, una línea jurisprudencial que comienza con las sentencias Internationale Handelsgesellschaft de 17 de diciembre de 1970 y Nold de 14 de mayo de 1974, proclama la protección de los derechos fundamentales en el derecho comunitario como principios generales del derecho. Ello significa que la identificación de los derechos y la determinación de su alcance es tarea de la propia jurisprudencia. El Tribunal de Luxemburgo, para encuadrar su discrecionalidad en este ámbito, declara que su elaboración jurisprudencial de los derechos fundamentales tendrá dos fuentes de inspiración: las tradiciones constitucionales comunes a los Estados miembros y el Convenio Europeo de Derechos Humanos, del que, por lo demás, todos los Estados miembros son parte. Desde entonces, el Tribunal de Justicia de las Comunidades Europeas se ha apoyado con frecuencia en el Convenio Europeo de Derechos Humanos para resolver asuntos en que estaban en juego derechos fundamentales. Esta construcción jurisprudencial recibió cierto respaldo en el preámbulo del Acta Unica Europea de 1986, donde se habla de «reafirmar muy especialmente los principios de la democracia y el respeto del Derecho y de los derechos humanos que ellos propugnan»; y más tarde fue definitivamente legitimada por el Tratado de Maastricht de 1992. Así, encapsulando en una 
comunitarias (reglamentos, directivas, etc.) que vulnere un derecho fundamental podrá ser anulado por el Tribunal de Justicia de las Comunidades Europeas. Ahora bien, la caracterización como principios generales del derecho agota la operatividad de los derechos fundamentales en el derecho derivado. Los principios generales del derecho no son jerárquicamente superiores al derecho originario, de manera que éste es inmune a eventuales reproches de vulneración de derechos fundamentales. Y ello no se refiere sólo a los Tratados constitutivos, sino también a los actos a que aquéllos se remiten para su desarrollo. Piénsese en las decisiones del Consejo con ulterior ratificación por los Estados miembros para regular la elección del Parlamento Europeo o el sistema de recursos propios (arts. 190 y 269 del Tratado de la Comunidad Europea respectivamente) o en la revisión puramente comunitaria de los estatutos del Banco Central Europeo y del propio Tribunal de Justicia (arts. 107 y 225 del Tratado de la Comunidad Europea respectivamente). La situación es distinta cuando los derechos fundamentales no se protegen como principios generales del derecho, sino como obligación dimanante de la condición de parte en el Convenio Europeo de Derechos Humanos. Entonces no cabe invocar las propias normas constitucionales para justificar la vulneración de derechos reconocidos por el Convenio Europeo o, dicho de otra manera, el Convenio Europeo vincula a las partes en su conjunto, incluidos sus respectivos poderes constituyentes.

Por todo ello, muchos han defendido que la salida del callejón pasaría por la adhesión de la Unión Europea en cuanto tal al Convenio Europeo de Derechos Humanos, de manera que éste fuera vinculante por sí mismo, no ya como mera«fuente de inspiración». Esta idea, sin embargo, ha encontrado no pocas dificultades.

\section{II}

La segunda faceta de la relación entre la Unión Europea y el Convenio Europeo de Derechos Humanos es, precisamente, la eventual adhesión de aquélla e éste. La cuestión, que venía debatiéndose desde tiempo atrás, se materializó cuando, a mediados de los años noventa, la Comisión solicitó al Tribunal de Justicia, de conformidad con lo previsto en el art. 300 (ex 228) del Tratado de la Comunidad Europea, dictamen acerca de la compatibilidad con los Tratados constitutivos de una eventual adhesión de la Comunidad Europea al Convenio Europeo de Derechos Humanos. El Tribunal de Justicia de las Comunidades Europeas, mediante Dictamen de 28 de marzo de 1996, dio una respuesta negativa.

El Tribunal de Luxemburgo consideró que, en el estado de desarrollo en que entonces se encontraba el derecho comunitario, la Comunidad Europea — recuérdese que a la Unión Europea no le había sido expresamente atribuida personalidad jurídica - no podía adherirse al Convenio Europeo de Derechos Humanos. La justificación se desplegaba en dos fases: primero, se constata que los Tratados constitutivos no han dotado a la Comunidad Europea de competencia alguna en materia de derechos humanos; segundo, se afirma que, así las cosas, habría que recurrir a la cláusula de cierre del art. 308 (ex 235) del Tratado de la Comunidad Europea, y ello no sería admisible dadas las dimensiones de la medida. En palabras del propio Dictamen de 28 de marzo de 1996, «una modificación semejante del régimen de protección de los derechos humanos en la Comunidad, cuyas implicaciones institucionales serían asimismo fundamentales tanto para la Comunidad como para los 
fórmula sintética la ya consolidada construcción jurisprudencial, el art. 6 del Tratado de la Unión Europea dispone en su apartado segundo: «La Unión respetará los derechos fundamentales tal y como se garantizan en el Convenio Europeo para la Protección de los Derechos Humanos y de las Libertades Fundamentales firmado en Roma el 4 de noviembre de 1950, y tal y como resultan de las tradiciones constitucionales comunes a los Estados miembros como principios generales del Derecho comunitario».

Todo esto es bien conocido, por lo que no vale la pena extenderse más sobre ello ahora. (Dentro de la ingente literatura sobre la protección de los derechos fundamentales en el ordenamiento comunitario, véase, por ejemplo, el claro resumen que han hecho recientemente B. Nascimbene y C. Sanna, «Art. 6 TUE», en A. Tizzano, ed., Trattati dell'Unione Europea e della Comunità Europea, Giuffrè, Milán, 2004, p. 49 ss.).

Sí conviene, en cambio, hacer algunas observaciones sobre la utilización del Convenio Europeo de Derechos Humanos por el Tribunal de Justicia de las Comunidades Europeas. La primera y principal es que dicha utilización se ha venido haciendo sin que la Unión Europea $-\mathrm{O}$, para hablar con mayor precisión, la Comunidad Europea, que es la única formalmente dotada de personalidad jurídica - se haya adherido al Convenio Europeo. De aquí se sigue que la interpretación que el Tribunal de Justicia de las Comunidades Europeas hace de los derechos garantizados por el Convenio Europeo no tiene por qué coincidir necesariamente con la que hace el intérprete oficial del mismo, esto es, el Tribunal Europeo de Derechos Humanos. De hecho, ha habido discrepancias. Tal vez la más notoria haya sido la relativa a si el derecho a la inviolabilidad del domicilio cubre a las personas jurídicas, que el Tribunal de Estrasburgo afirmaba y el Tribunal de Luxemburgo negaba. Sólo con la sentencia Roquette Frères de 22 de octubre de 2002, ha rectificado el Tribunal de Justicia de las Comunidades Europeas, admitiendo por fin que también las personas jurídicas gozan del derecho a la inviolabilidad del domicilio. (Véase A. López Basaguren, «La interpretación divergente entre el TEDH y el TJCE sobre el derecho a la inviolabilidad del domicilio de las personas jurídicas», en Revista Española de Derecho Europeo no 5, 2003).

Como ha observado agudamente Joël Rideau, estas discrepancias entre ambos Tribunales no tienen fácil solución, ya que no existe una clara jerarquía institucional entre ellos, del mismo modo que no existe jerarquía normativa alguna entre el Convenio Europeo de Derechos Humanos y los Tratados constitutivos de la Unión Europea (»Los derechos fundamentales comunitarios y los derechos humanos», en F.J. Matía Portilla, ed., La protección de los derechos fundamentales en la Unión Europea, Civitas, Madrid, 2002, p. 61 ss.). Todos los Estados miembros de la Unión Europea son parte del Convenio Europeo de Derechos Humanos. Y no puede decirse que una vinculación sea más fuerte que la otra. Es verdad que la pertenencia a la Unión Europea implica la aceptación del principio de colaboración leal (art. 10 del Tratado de la Comunidad Europea), por no hablar del principio de primacía del derecho comunitario; pero no es menos cierto que la pertenencia al Convenio Europeo de Derechos Humanos implica la aceptación de la obligatoriedad de las sentencias del Tribunal de Estrasburgo. Se trata, en suma, de dos vinculaciones cuyo fundamento último se halla, en ambos casos, en acuerdos internacionales concluidos por Estados.

Téngase en cuenta, por lo demás, que la caracterización de los derechos fundamentales como principios generales del derecho tiene ciertas limitaciones Qué duda cabe que supone imponer una barrera a las instituciones comunitarias, y también a las autoridades nacionales cuando aplican el derecho comunitario. Así, cualquier acto de las instituciones 
peligroso para el propio proceso de integración europea reconocer la jurisdicción de un Tribunal, como es el de Estrasburgo, formado en parte por personas provenientes de países de reciente democratización. (Véase, en este sentido, el alegato de A. Rodríguez Bereijo, La Carta de Derechos Fundamentales de la Unión Europea, lección inaugural del año académico en la Universidad Autónoma de Madrid, U.A.M. Madrid, 2000). Este modo de pensar, además, no es ajeno a la desconfianza que hacia el Tribunal de Estrasburgo sienten quienes lo reputan demasiado dado a aventuras, como consecuencia de no estar anclado en una entidad política. Georges Vedel lo expresó con claridad: «Hay que desconfiar de los organismos que no se basan en una responsabilidad concreta [...]. Cuando el Tribunal de Justicia de las Comunidades Europeas decide algo, su decisión tiene cierta influencia sobre un organismo que depende de ella. Está, por tanto, obligado a tener en cuenta la estructura en su conjunto. El Tribunal Europeo de Derechos Humanos no está sujeto a nada. Decide desde las alturas celestiales» («Constituciones, reglas y hechos: una conversación con el profesor Georges Vedel», en Anuario de derecho Constitucionaly Parlamentario no 6, 1994, p. 32). Frente a ello, la única respuesta creíble es sostener que debe existir una armonía de valores entre la gran Europa y la pequeña Europa, que, por lo demás, cada día es menos pequeña. (Véase A. Saiz Arnaiz, «Constitución y derechos: la Carta 'retocada', el Convenio Europeo de Derechos Humanos y la Parte II del proyecto de Tratado», en E. Albertí Rovira, ed., El proyecto de una nueva Constitución europea, Tirant lo Blanch, Valencia, 2004, p. 354).

Este era, así, el punto en que había quedado la cuestión: la adhesión de la Unión Europea al Convenio Europeo de Derechos Humanos no sería posible sin una específica reforma de los Tratados constitutivos que la autorizase. Con posterioridad, sin embargo, se ha producido la elaboración de la Carta de Derechos Fundamentales de la Unión Europea, proclamada en la cumbre de Niza de 7 de diciembre de 2000; y se ha producido, asimismo, la elaboración y aprobación del Tratado por el que se instituye una Constitución para Europa, en la actualidad pendiente de ratificación. La Constitución para Europa incorpora en su texto la Carta de Derechos Fundamentales de la Unión Europea; lo que significa que, una vez entrada en vigor la Constitución para Europa, la Carta gozará de la fuerza normativa propia de las normas constitucionales. Sin embargo, aun estableciendo su propio catálogo de derechos, la Constitución para Europa no abandona la vieja idea de la adhesión de la Unión Europea al Convenio Europeo de Derechos Humanos, sino que la relanza. En efecto, el art. I-9 de la futura Constitución para Europa establece:

«1. La Unión reconoce los derechos, libertades y principios enunciados en la Carta de los Derechos Fundamentales que constituye la Parte II.

2. La Unión se adherirá al Convenio Europeo para la Protección de los Derechos Humanos y de las Libertades Fundamentales. Esta adhesión no modificará las competencias de la Unión que se definen en la Constitución.

3. Los derechos fundamentales que garantiza el Convenio Europeo para la Protección de los Derechos Humanos y de las Libertades Fundamentales y los que son fruto de las tradiciones constitucionales comunes a los Estados miembros forman parte del Derecho de la Unión como principios generales».

Varios aspectos de este precepto merecen ser destacados. En primer lugar, si la Constitución para Europa es ratificada, ya no habrá carencia alguna de base jurídica para la adhesión de la Unión Europea al Convenio Europeo de Derechos Humanos. Más aún, 
Estados miembros, tendría una envergadura constitucional y sobrepasaría pues, por su naturaleza, los límites del artículo 235. Dicha modificación únicamente puede realizarse a través de una modificación del Tratado».

Esta decisión jurisdiccional no es del todo convincente; y ello, sucintamente expresado, porque no puede decirse que los derechos fundamentales sean una materia sobre la que se tiene - $\mathrm{O}$ no se tiene- competencia. En un contexto liberal-democrático, los derechos fundamentales son, antes que cualquier otra cosa, barreras frente a los poderes públicos. Precisamente por ello, no cabe negar a una entidad que se quiere liberal-democrática la posibilidad de adherirse al principal instrumento internacional de protección de los derechos humanos en la región. Más aún: en 1996 la Comunidad Europea poseía competencia para usar los derechos fundamentales como medio de su política de cooperación al desarrollo. El art. 177 (ex 130 U) del Tratado de la Comunidad Europea, que había sido introducido por el Tratado de Maastricht de 1992, dispone en su apartado segundo: «La política de la Comunidad en este ámbito contribuirá al objetivo general de desarrollo y consolidación de la democracia y del Estado de derecho, así como al objetivo de respeto de los derechos humanos y de las libertades fundamentales». No deja de haber, pues, cierta hipocresía en negar que exista una competencia ad intra allí donde existe expresamente ad extra con respecto a países en vías de desarrollo.

Dicho esto, forzoso es reconocer que alguna razón asistía al Tribunal de Luxemburgo cuando señaló que una eventual adhesión al Convenio Europeo de Derechos Humanos tendría «envergadura constitucional». En dos sentidos, efectivamente, puede decirse que una eventual adhesión de la Unión Europea al Convenio Europeo de Derechos Humanos sería constitucionalmente relevante. Por un lado, como bien muestra la historia de los Estados Unidos, la simple existencia de un catálogo de derechos común opera como un factor centrípeto, pues hace pensar a muchos que los derechos que se ostentan frente al poder federal se deben tener también frente al poder estatal. El catálogo de derechos federal sería, según este modo de ver las cosas, un mínimo irrenunciable; lo que conduce a justificar lo que los norteamericanos denominan la incorporation, esto es, que el Tribunal Supremo declare que un derecho reconocido en la Constitución federal vincula a los Estados. (Véase, por ejemplo, H.J. Abraham, Freedom and the Court: Civil Rights and Liberties in the United States, $5^{\mathrm{a}}$ ed., Oxford University Press, Nueva York/Oxford, 1988, p. 38 ss.). Por otro lado, es claro que la aceptación de la jurisdicción del Tribunal Europeo de Derechos Humanos sobre la Unión Europea afectaría a la posición del Tribunal de Justicia. Ello no debe ser entendido como un simple problema de celos, por más que a nadie le guste aceptar a un competidor. Se trata, más bien, de que el Tribunal de Justicia es consciente del papel central que ha desempeñado en el proceso de integración europea; papel que sería más difícil de jugar en compañía de otro Tribunal, cuya lógica institucional, por lo demás, no está orientada hacia la integración europea, sino sólo hacia la salvaguardia de los derechos humanos. (Véase, en este sentido, la lúcida reflexión de J.A. Carrillo Salcedo, El Convenio Europeo de Derechos Humanos, Tecnos, Madrid, 2003. p. 123 ss.). Téngase presente, por lo demás, que el Tribunal de Justicia de las Comunidades Europeas siempre ha sido hostil a la aparición de órganos jurisdiccionales que pudieran interferir en su labor de guardián de las esencias supranacionales, como lo demuestra su Dictamen de 14 de diciembre de 1991 relativo al Espacio Económico Europeo.

A todo ello habría que añadir la reticencia de no pocos observadores que consideran 
cho comunitario una posición subordinada al derecho originario, pero superior al derecho derivado (sentencia Alemania c. Consejo de 5 de octubre de 1994). Así, en la medida en que se admita que las disposiciones del Convenio Europeo son suficientemente claras y precisas —lo que sería verosímil, habida cuenta de su amplia elaboración jurisprudencialhabría que concluir que aquél tendría eficacia directa en el ordenamiento comunitario y ocuparía una posición intermedia entre el derecho originario y el derecho derivado. Esta conclusión, sin embargo, podría ser cuestionada a la luz del inciso del apartado tercero del art. I-9 de la Constitución para Europa donde, en perfecta continuidad con la situación actual, se dispone que los derechos fundamentales del Convenio Europeo «forman parte del Derecho de la Unión como principios generales». ¿Cambia algo esta caracterización como principios generales, en vez de como normas convencionales directamente aplicables? Desde el punto de vista de la posición jerárquica ocupada, ciertamente no. Ya se vio más arriba que también los principios generales del derecho ocupan una posición intermedia entre el derecho originario y el derecho derivado; lo que implica, entre otras cosas, que el Convenio Europeo no podría ser utilizado como canon de validez de normas de derecho originario. Cosa distinta es hasta qué punto ello es compatible con el propio Convenio Europeo de Derechos Humanos, que, como se ha dicho, vincula a las partes en su integridad. Y hay que tener en cuenta que las colisiones entre Convenio Europeo y derecho originario, como se comprobará más adelante, no son inconcebibles. Por lo demás, tampoco desde el punto de vista de la eficacia directa parece que cambien mucho las cosas. Los principios generales del derecho pueden desplegar eficacia directa, naturalmente siempre que previamente hayan sido identificados y delimitados por el Tribunal de Justicia de las Comunidades Europeas. ¿Significa ello que el art. I-9 de la Constitución condiciona la invocabilidad de los derechos reconocidos en el Convenio Europeo a su previa aceptación e interpretación por el Tribunal de Justicia? Ello no tendría mucho sentido, porque ésa es precisamente la situación actual. Así entendido, el art. I-9 haría inútil la adhesión de la Unión Europea al Convenio Europeo de Derechos Humanos.

En cuarto y último lugar, conviene destacar que los arts. II-112 y II-113 de la Constitución para Europa establecen dos reglas para resolver, en el ámbito del derecho de la Unión Europea, las posibles fricciones entre la Carta y el Convenio Europeo. El art. II-112 ordena que los derechos reconocidos en la Carta sean interpretados a la luz del Convenio Euroepo; lo que, bien mirado, constituye una norma interpretativa similar a la establecida en el art. 10 de la Constitución española. El art. II.113, por su parte, dispone que la Carta no supone disminución del nivel de protección de los derechos otorgado por el Convenio Europeo. Así, el Convenio Europeo, en caso de ser más beneficioso que la Carta en algún punto, será de aplicación con el valor de principios generales.

Existe, en fin, una tercera faceta de la relación entre la Unión Europea y el Convenio Europeo de Derechos Humanos. Se trata de los casos en que el Tribunal Europeo de Derechos Humanos ha sido llamado a enjuiciar, de manera directa o indirecta, la conformidad al Convenio Europeo de actos de la Unión Europea. (Sobre este tema, véase el excelente y completo estudio de S. Sanz Caballero, «Interferencias entre el derecho comu- 
existirá un mandato constitucional al respecto, de manera que las instituciones de la Unión Europea habrán de hacer todo lo que esté en su mano para lograr dicha adhesión. Ello podría exigir una previa revisión del Convenio Europeo de Derechos Humanos, que no contempla como partes a entidades distintas de los Estados. Obsérvese, por lo demás, que el citado art. I-9 se refiere a la adhesión de la Unión Europea en su conjunto, a la que el art. I-7 de la propia Constitución para Europa dota expresamente de personalidad jurídica. Ello implica, a efectos prácticos, que el Convenio Europeo será aplicable, en principio, también a aquellos ámbitos de actividad de la Unión Europea que actualmente no son comunitarios.

En segundo lugar, el art. I-9 tiene cuidado en recalcar que la adhesión al Convenio Europeo de Derechos Humanos «no modificará las competencias de la Unión que se definen en la Constitución». El constituyente está seriamente preocupado por la posibilidad de que el reconocimiento de derechos fundamentales no conduzca a una expansión subrepticia de las competencias de la Unión Europea, en línea con la arriba mencionada tendencia centrípeta de toda declaración de derechos. Tan es así que una norma similar se establece con respecto a los derechos reconocidos en la Carta, es decir, en la Parte II de la Constitución para Europa. Dice el apartado segundo del art. II-111: «La presente Carta no amplía el ámbito de aplicación del Derecho de la Unión más allá de las competencias de la Unión, ni crea ninguna competencia o misión nuevas para la Unión, ni modifica las competencias y misiones definidas en las demás Partes de la Constitución». Todo ello significa que el constituyente contempla los derechos fundamentales, tanto de la Carta como del Convenio Europeo, sólo como una barrera frente al poder. No cabe legislar so pretexto de dar plena efectividad a los derechos fundamentales, ni realizar una política de derechos fundamentales, ni menos aún utilizarlos como títulos competenciales. Hasta qué punto, en una época caracterizada por la cultura de los derechos, es realista esta aspiración a la contención de los derechos fundamentales es algo que sólo el tiempo podrá decir. (Un detenido análisis de esta cuestión se halla en P. Biglino Campos, «Derechos fundamentales y competencias de la Unión», en Revista de Derecho Comunitario Europeo n 14, 2003, p. 45 ss.).

En tercer lugar, no es del todo claro qué valor tendría el Convenio Europeo de Derechos Humanos dentro del derecho de la Unión Europea. Como es sabido, el Convenio Europeo no exige su incorporación al derecho interno de los Estados parte, ni menos aún que esa incorporación se haga con un determinado rango normativo. Siguiendo la pauta del derecho internacional, el Convenio Europeo sólo impone a los Estados una obligación de medios, no de resultado; es decir, están obligados a respetar los derechos garantizados por el Convenio Europeo, no a transformar éste en norma nacional. En pocas palabras, el valor del Convenio Europeo en el derecho interno depende del principio, monista o dualista, que rige en cada ordenamiento las relaciones entre derecho internacional y derecho interno. ¿Cuál sería, entonces, la situación en el derecho de la Unión Europea? La Unión Europea es, más por elaboración jurisprudencial que por imperativo de normas escritas, moderadamente monista; es decir, tiende a aceptar que los tratados internacionales por ella celebrados son, por sí mismos, fuente de su propio ordenamiento. A este respecto, el Tribunal de Justicia de las Comunidades Europeas ha establecido dos criterios básicos: primero, la eficacia directa de los tratados internacionales sólo está condicionada a que sus disposiciones sean suficientemente claras y precisas (sentencia Demirel de 30 de septiembre de 1987); segundo, los tratados internacionales ocupan en la jerarquía de fuentes del dere- 
que concluir que se trata de actos de derecho originario, como tales no sujetos a la jurisdicción del Tribunal de Jusiticia de las Comunidades Europeas. (Véase, por todos, T.C. Hartley, The Foundations of European Community Law, $2^{\mathrm{a}}$ ed., Clarendon Press, Oxford, 1988, p. 24). Esto quiere decir que la recurrente no hubiera podido ni siquiera plantear su agravio ante el juez encargado de conocer del derecho de la Unión Europea. He aquí un ejemplo de cómo la colisión entre el Convenio Europeo y el derecho originario de la Unión Europea dista de ser inverosímil.

Viene después la sentencia Dangeville c. Francia de 16 de marzo de 2002, en la que el Tribunal Europeo de Derechos Humanos conoce de un recurso por la falta de transposición tempestiva de una directiva comunitaria en materia tributaria. El Tribunal de Estrasburgo estimó el recurso, considerando que los pagos que no habrían debido hacerse de haber estado transpuesta la directiva suponen una violación del derecho a la propiedad privada, consagrado por el art. 1 del Protocolo Adicional al Convenio Europeo. (Véase C. Pérez González, «La incidencia de la jurisprudencia del Tribunal Europeo de Derechos Humanos en la efectiva protección de los derechos comunitarios de los particulares», en Revista Española de Derecho Europeo no 8, 2003, p. 737 ss.). Este criterio ha sido luego reiterado en la sentencia Cabinet Diot c. Francia de 22 de julio de 2003. Sin duda, se está aquí dentro de la esfera de actos - mejor dicho, omisiones - imputables a los Estados parte en el Convenio Europeo de Derechos Humanos y, en este sentido, no cabe reprochar al Tribunal de Estrasburgo extralimitación alguna.

Pero hay un aspecto menos convincente en las sentencias Dangeville y Cabinet Diot: el Tribunal Europeo de Derechos Humanos puede acabar interfiriendo con el régimen jurídico de la responsabilidad extracontractual de los Estados miembros por incumplimiento del derecho comunitario, tal como se desprende de la rica jurisprudencia del Tribunal de Justicia de las Comunidades Europeas inaugurada por la sentencia Francovich de 19 de noviembre de 1991. El problema no es tanto si la «satisfacción equitativa» que prevé el art. 41 del Convenio Europeo coincidiría o no con la indemnización debida por responsabilidad extracontractual por incumplimiento del derecho comunitario, sino si los requisitos de ésta última y los de la violación del citado art. 1 del Protocolo Adicional al Convenio Europeo son similares. El riesgo de la incipiente línea jurisprudencial apuntada por las referidas sentencias Dangeville y Cabinet Diot, en otras palabras, es que el Tribunal de Estrasburgo acabe por desvirtuar los requisitos que el derecho comunitario impone para apreciar responsabilidad extracontractual de los Estados miembros. Lo que parece, en todo caso, exigible al Tribunal de Estrasburgo es que los recurrentes hayan agotado las vías internas (art. 35 del Convenio Europeo de Derechos Humanos), las cuales, tratándose de normas de la Unión Europea consisten, cuanto menos, en una previa acción de responsabilidad extracontractual contra el Estado por incumplimiento del derecho comunitario ante el correspondiente juez nacional, más la posible cuestión prejudicial ante el Tribunal de Luxemburgo. En suma, si un día el Tribunal de Estrasburgo ha de decir que la jurisprudencia del Tribunal de Luxemburgo sobre responsabilidad extracontractual de los Estados miembros es demasiado restrictiva desde el punto de vista del derecho fundamental de propiedad privada, que lo diga; pero lo que no sería de recibo es que se desarrollasen dos jurisprudencias alternativas sobre la reparación debida por los Estados en caso de incumplimiento del derecho comunitario.

Tanto la sentencia Matthews como las sentencias Dangeville y Cabinet Diot se ocupaban 
nitario y el Convenio Europeo de Derechos Humanos», en Revista de Derecho Comunitario Europeo no 17, 2004, p. 117 ss.). En esta sede, tal vez sea más claro hacer una narración cronológica, en lugar de un análisis sistemático.

Sin perjuicio de algún precedente aislado en las decisiones de la desaparecida Comisión de Derechos Humanos, la primera vez que el Tribunal Europeo de Derechos Humanos se ocupó directamente de un acto relacionado con la Unión Europea fue en la sentencia Matthews c. Reino Unido de 18 de febrero de 1999. Se trataba de la reclamación de una ciudadana de Gibraltar contra la ley británica que no incluía a los gibraltareños entre los titulares del derecho de sufragio en las elecciones al Parlamento Europeo. La recurrente entendía que ello vulneraba el derecho a elecciones periódicas y libres, consagrado en el art. 3 del Protocolo Adicional al Convenio Europeo. Hay que tener presente que la ley impugnada había sido dictada en aplicación de lo dispuesto por la Decisión del Consejo de 20 de septiembre de 1976, que aprueba el Acta sobre Elección de los Representantes en el Parlamento Europeo. En su Anexo II se dice que «el Reino Unido aplicará las disposiciones de la presente Acta únicamente con respecto al Reino Unido». Pues bien, el Tribunal Europeo de Derechos Humanos estimó el recurso, condenando al Reino Unido por violación del derecho a elecciones libres y periódicas. La sentencia Matthews es, sin duda, criticable en cuanto al fondo. Una cosa es que los Estados parte en el Convenio Europeo se comprometan a tener elecciones libres y periódicas, y otra muy distinta que el Tribunal de Estrasburgo pueda sustituir su criterio al de los Estados para decidir qué territorios están dentro de la Unión Europea. En otras palabras, que Gibraltar esté dentro del ámbito espacial de aplicación del Convenio Europeo no implica su inclusión automática dentro del ámbito espacial de la Unión Europea, como lo demuestra que el citado Anexo II preveía su aplicación únicamente al Reino Unido en sentido estricto, del que Gibraltar no forma parte. (Véase, en este orden de consideraciones, la dura crítica L.I. Sánchez Rodríguez, «Sobre el derecho internacional de los derechos humanos y comunitario europeo», en Revista de Derecho Comunitario Europeo no 5, 1999, p. 95 ss.).

Hay, sin embargo, una segunda faceta de la sentencia Matthews sobre la que vale la pena reparar. Con independencia del fondo del asunto, el Tribunal Europeo de Derechos Humanos seguramente tiene razón en considerar que los Estados parte en el Convenio Europeo están vinculados por éste incluso cuando actúan en cumplimiento de obligaciones contraídas en virtud de tratados internacionales o de su pertenencia a organizaciones internacionales. Ante una reclamación por vulneración del Convenio Europeo, los Estados no pueden invocar en su descargo que actuaban por imperativos derivados de su pertenencia a la Unión Europea. La vigencia y la fuerza del Convenio Europeo de Derechos Humanos no se ha visto afectada por los Tratados constitutivos de la Unión Europea, celebrados por algunos de los Estados parte en aquél. Que el Tribunal Europeo de Derechos Humanos conozca de actos de los Estados producidos en cumplimiento del derecho de la Unión Europea no es, en principio, objetable.

Una última observación acerca de la sentencia Matthews: es muy dudoso que la Decisión del Consejo de 20 de septiembre de 1976, en cumplimiento de la cual fue dictada la ley británica recurrida, hubiera podido ser impugnada ante el Tribunal de Justicia de las Comunidades Europeas. Aunque su naturaleza jurídica no es clara, prevalece la opinión de que las decisiones adoptadas sobre la base del art. 190 (ex 138) del Tratado de la Comunidad Europea constituyen un forma simplificada de revisión del propio Tratado. Por ello, hay 
Europeo de actos de la Unión Europea; lo que habría provocado, muy probablemente, una crisis con ésta. La prudencia, sin embargo, es relativa, porque el Tribunal Europeo de Derechos Humanos no ha dicho que los actos de la Unión Europea — que, guste o no, no es parte en el Convenio Europeo- no son susceptibles de control mediante su imputación al conjunto de los Estados miembros. En la sentencia Segi, había algún resquicio para justificar semejante imputación, ya que se trataba de un acto dictado en materia de cooperación policial y judicial, el llamado «tercer pilar», en que el proceso decisional es eminentemente intergubernamental; y, aun así, no hay que olvidar que los actos adoptados por una organización internacional no son lo mismo que una suma de actos de los Estados que la forman. Ahora bien, en la sentencia Senator Lines la imputación del acto impugnado al conjunto de los Estados miembros de la Unión Europea carece de justificación alguna. Alemania había apoyado siempre a la empresa recurrente, de manera que el dilema es claro: o se excluye a este país, con la consecuencia de que la identificación entre la Unión Europea y el conjunto de los Estados miembros cae por su base; o se incluye a dicho país — como, en efecto, se hizo-, con la consecuencia de que dicha identificación es manifiestamente una ficción. Pero hay aún un argumento más poderoso: el acto impugnado era una resolución judicial, que difícilmente puede presentarse como la confluencia de voluntades de una serie de Estados. En resumen, habría sido más prudente y más ajustado a la realidad jurídica que el Tribunal de Estrasburgo no se hubiera guardado una bala en la recámara y hubiera reconocido sin ambages que los actos de la Unión Europea en cuanto tal escapan de su jurisdicción.

La jurisprudencia del Tribunal Europeo de Derechos Humanos en relación con la Unión Europea es, así, muy poco convincente. Es verdad que los actos —u omisiones — de los Estados en cumplimiento de obligaciones comunitarias están sometidos al Convenio Europeo; pero la sentencia Matthews se extralimitó al interferir en la determinación del ámbito espacial de las normas de la Unión Europea; y las sentencias Dangeville y Cabinet Diot han abierto la puerta para una doble vía de reparación por incumplimiento estatal del derecho comunitario, que carece de justificación. En cuanto a la sentencia Senator Lines, se acaba de ver cómo se abstiene de decir que el Tribunal de Estrasburgo carece de jurisdicción sobre los actos de la Unión Europea. Tal vez la decisión más acertada haya sido la sentencia Segi, porque allí ese silencio sobre la propia jurisdicción tenía algún apoyo en la naturaleza intergubernamental del acto impugnado. 
de actos $-\mathrm{u}$ omisiones- de los Estados parte en el Convenio Europeo de Derechos Humanos relacionados con su pertenencia a la Unión Europea. Ha habido, sin embargo, intentos de que el Tribunal de Estrasburgo se pronunciara directamente sobre actos de la Unión Europea. El obstáculo de que ésta no sea parte del Convenio Europeo se ha intentado salvar dirigiendo el recurso contra todos y cada uno de los Estados miembros de la Unión, todos los cuales son también parte en el Convenio Europeo. Es claro que esta estrategia parte del presupuesto de que los actos de la Unión Europea son, en todo caso, imputables al conjunto de sus Estados miembros. El primer caso en que se exploró esta vía fue el resuelto por la sentencia Segi y otros c. Austria, Bélgica, Dinamarca, Finlandia, Francia, Alemania, Grecia, Irlanda, Italia, Luxemburgo, Países Bajos, Portugal, España, Suecia y Reino Unido de 23 de mayo de 2002, en que se impugnaba la inclusión de cierta organización en la lista de organizaciones consideradas terroristas por la Unión Europea. El Tribunal Europeo de Derechos Humanos desestimó la reclamación sin examinar la posible legitimación pasiva del conjunto de Estados miembros de la Unión Europea, ni entrar en el fondo del asunto. Se limitó a constatar que las entidades recurrentes no coincidían con la organización incluida en la lista, por lo que no estaban directamente afectadas; es decir, no eran «víctima de una violación» de derechos en el sentido del art. 34 del Convenio Europeo. Ciertamente, éste era un caso peculiar, del que era difícil esperar una innovación importante en la actitud del Tribunal Europeo de Derechos Humanos frente a reclamaciones contra actos de la Unión Europea; pero la cuestión había quedado planteada.

Y se confiaba que fuera resuelta por la muy esperada sentencia DSR-Senator Lines GmbH c. Austria, Bélgica, Dinamarca, Finlandia, Francia, Alemania, Grecia, Irlanda, Italia, Luxemburgo, Países Bajos, Portugal, España, Suecia y Reino Unido de 10 de marzo de 2004, dictada en un caso mucho menos excepcional. El recurso, interpuesto en el año 2000, traía causa de una multa por infracción del derecho comunitario de la competencia. Al recurrir la multa ante el Tribunal de Primera Instancia, la empresa sancionada solicitó asimismo la suspensión cautelar, con el argumento de que su ejecución la conduciría inmediatamente a la quiebra. La solicitud de suspensión fue rechazada. Contra esta desestimación de medida cautelar presenta recurso ante el Tribunal Europeo de Derechos Humanos, por infracción del derecho a un juicio equitativo (art. 6 del Convenio Europeo). Lo más destacable de este asunto, como muy bien ha mostrado Duina Marinas Suárez, es la deliberada tardanza del Tribunal de Estrasburgo en resolver, debida seguramente a su voluntad de no interferir en el proceso de aprobación de la Carta Europea de Derechos Fundamentales primero, y de la Constitución para Europa — que incluye, como se vio, el mandato de adhesión al Convenio Europeo- después (»Senator Lines c. los quince Estados miembros de la Unión Europea», en Revista Española de Derecho Europeo no 11, 2004, p. 475 ss.). Es probable, en efecto, que una resolución agresiva hacia la Unión Europea hubiese determinado un resultado distinto al arriba mencionado art. I-9 de la Constitución para Europa. Pues bien, cuando en septiembre de 2003 el Tribunal de Primera Instancia anula la multa, cuya ejecución entretanto no había sido instada por la Comisión, el Tribunal Europeo de Derechos Humanos entra, por fin, en el asunto; y, como para entonces el interés del recurrente había desaparecido, éste no podía ser considerado «víctima de una violación» de derechos y procedía desestimar el recurso.

Las sentencias Segi y Senator Lines son, así, relativamente prudentes. Son prudentes, porque han evitado pronunciarse directamente sobre la conformidad con el Convenio 
